\title{
Employment and Innovation in U.S. Media Industries. 2004-2018
}

\author{
Humberto Merritt \\ Centro de Investigaciones Económicas, Administrativas y Sociales (CIECAS) \\ Instituto Politécnico Nacional (IPN), Lauro Aguirre \#120, Col. Agricultura \\ Mexico City, 11360 MÉXICO \\ E-mail: hmerritt@ipn.mx \\ https://orcid.org/0000-0003-3580-7325
}

\begin{abstract}
Information and Communications Technologies have transformed several activities through digitization. Among the most significant transformations are those experienced by the paper, printing, publishing, and broadcasting industries, ranging from shrinking markets to unpredictable customers' choices. As a result, several job routines and labor skills have become obsolete. Although widespread digitization has produced declining employment rates, average wages have continued to grow. In this paper, we carry out trend analysis to test the following hypotheses: First, digitization has altered traditional routines and skills, resulting in declining employment rates. Second, productivity has grown because firms have recruited more skilled workers with higher wages. We analyze employment and wage tendencies in four communications and media sectors to test these hypotheses. We compare historical data in each industry from 2004 to 2018. To this end, we draw on the Occupational Employment Statistics (OES) Survey from the Bureau of Labor Statistics of the U.S. Department of Labor.
\end{abstract}

\section{Keywords}

United States; ICT; industrial innovation; technical change; digitization; digital convergence; employment; wages;

\section{Introduction}

The World Wide Web materialized in 1991 thanks to the development of the hypertext markup language (HTML) at the European Center for Nuclear Research (CERN) in Switzerland from a project headed by Tim Berners-Lee and Robert Caillau (Greenstein, 2015). Within a few months, the computer program called the Mosaic browser appeared. These two events transformed the Internet from an academic communication tool into a global interface phenomenon (McCullough, 2018). The Internet's incessant penetration has proved to be such a disruptive force that many industries have entirely been transformed by the resultant digitization of products and services (Parker, Van Alstyne, \& Choudary, 2017).

The digital revolution emerging from Information and Communications Technology (ICT) has notably transformed key firms and industries in the United States. For example, companies that 30 years ago were perceived as very strong and stable today have disappeared. Such was the fate of Kodak, Polaroid, and Blockbuster (Lucas \& Goh, 2009). In contrast, businesses that were almost unimagined back in the 1990s are now powerful corporations that dominate the economic landscape thanks to the Internet. These are the GAFA firms' cases: Google, Apple, Facebook, and Amazon, epitomizing the digital revolution that disrupts the worldwide economy (Martel, 2018; Parker et al., 2017). 
ICT penetration accelerated during 2020. The reliance of society on technology and online platforms grew during the COVID-19 pandemic. This drastic change impacted all industries and service sectors, especially health care, education, retail, travel, food, and government agencies. Therefore, home offices, remote videoconferences, and virtual activities exploded due to the lockdown, mobility restrictions, and social distancing (Heralth \& Heralth, 2020).

The transformation of economic activities has opened up new markets and demands for skilled workers that were non-existent thirty years ago. ICT system engineers, software developers, digital designers, big data analysts, and webmaster technicians are common professions today but were rarely known in the 1980s (Mayinka, Ramaswamy, Khanna \& Sarrazin, 2015). As a result, employment in the ICT sector has expanded quicker than in the rest of the economy (OECD, 2017).

This paper focuses on ICT's impact on critical socio-economic variables like jobs and wages by analyzing the Internet's effect on communications and media activities in four American sectors. By naming this process digitization, we mean the fusion of several formats (or applications) into a digital form (i.e., electronic format). Therefore, digitization has been a transforming technological weapon that has produced increasing value for users (Abaidi \& Vernette, 2018; McCullough, 2018; OECD, 1992, 2017; Yoffie, 1996). We focus on the cases of long-time established sectors such as printing and publishing, and airborne broadcasting, all of which have experienced hard times because of declining revenues. The paper is structured in six parts, including the introduction and conclusions. The following section introduces the notion of digitization.

\section{Digitization as a technological phenomenon}

Nicholas Negroponte and David Yoffie are widely regarded as pioneers of the digital economy concept. Negroponte famously predicted that interactive multimedia would become more booklike. The personal computer operated as a gateway to various information and entertainment services that would replace the T.V. set. He forecasted that "by the year 2005, Americans will spend more hours on the Internet (or whatever it is called) than watching network television" (Negroponte, 1995 , p. 58). A prediction has been so accurate that it ended in a dismal outcome for T.V. broadcasters. For his part, Yoffie conceptualized digitization as a technological revolution that would reshape the global economy. He envisioned that several new market opportunities would emerge by the turn of the twenty-first century. He accurately predicted the advent of huge investments in video-on-demand, interactive television, online services, and new forms of digital entertainment content (Yoffie, 1996). In hindsight, both were right in conceptualizing the surge of computers, communications, and consumer electronics as a brand-new economic paradigm.

The merging of communications, broadcasting, and computing was not unforeseeable, though. Since the late 1970s, there have been attempts to bring together the computer's data storage and handling capabilities with the versatility of transmitting voice and pictures that characterize radio and television. For example, Gaines (1998) reports the various platforms that sought to deliver personalized content through wires rather than airwaves. He describes the British Viewdata system, the French Minitel network, and the interactive Videotex platform as promising endeavors. However, their failure should be attributed to the lack of an integrated (and operational) universal communications network. To a large extent, the Internet emerged from three major technological advances: 1) Protocols for signal and data transmission/exchange (i.e., transmission control protocol, TCP/IP), 2) Advances in digital information compression, and 3) The already mentioned HTML standard (Greenstein, 2015). 
The Internet's most significant contribution to knowledge dissemination was its capability to upload, store, link, and index digitized documents, which helped emulate the printed publication medium, offering enhanced capabilities such as sound, video, and interactivity (OECD, 2017). The introduction of digital offerings of previously available printed material did not take too long to affect the involved industries. So, books, magazines, and newspapers (all of them paper-based reading stuff) began experiencing diminishing sales as soon as digital alternatives appeared on the Internet (Vogel, 2004). A similar fate befell the postal service stemming from the introduction of electronic mail messages. Yet, decay was softened by the interaction of modulating social forces, such as traditions and income (Meschi, Cherry, Pace, \& Petrova, 2011).

A caveat is worth noting: disruptive innovations are not necessarily radical in the sense that they might serve niche segments that value non-standard performance attributes. As Govindarajan \& Kopalle (2006) point out, disruptive technologies introduce a different performance package from mainstream technologies, inferior to them, and performance traits that are crucial to mainstream customers. Therefore, disruptive innovations generally compete through lower prices. So, why do some industries not pay attention to disruptive warnings and keep doing business as usual? According to Christensen \& Overdorf (2000), embedded routines are hard to modify because firms have invested heavily in their systems or equipment, being reluctant to waste resources to acquire newer technological capabilities. However, the rapid transformation of the media and communication sectors has pushed firms and consumers to evaluate their options.

In the U.S., content industries have experienced radical changes due to digitization and digital delivery since 2009, with their value chains being truly transformed (Martel, 2018; Meffert, Hazan, Wagener, Chappuis, et al., 2013). These changes have involved new competition across platforms and industries, cross-industry convergence, and alliances between digital content producers, such as television, cinema, music, games, and other content producing-industries, Internet portals, ICT firms, and consumer electronics firms (Mayunka et al., 2015; Parker et al., 2017).

According to McCulluogh (2018), different kinds of digital convergence are shaping the broadcasting market: 1) content convergence (broadcasting, telecommunications, video on demand and Internet Protocol T.V. (IPTV) delivered to home devices over the Internet, 2) business convergence (telecommunications, broadcasters, and full-media-play services), 3) network convergence (unified networks for telecommunications and broadcasting) and 4) final convergence (with different terminals being used for the same reception or the same terminal for various transmissions). As a result, digitization has provoked a wide array of firms to become increasingly involved in content distribution (e.g., telecommunications firms, Internet service providers, film studios, web portals, and mobile operators).

Digital technological change has particularly hit the T.V. industry: first, distributors frantically attempt to compete by packing content. Then, cable T.V. and free T.V. operators creating branded video on demand-VOD, and mobile T.V. services, with IPTV operators creating branded subscription VOD services, then mobile operators trying to develop branded TV/VOD services, and finally, distributors creating (or commissioning) enhanced content for mobile services, with content owners extending or creating distribution brands (Hesmondhalgh \& Lobato, 2019). 
On the business side, the disruptive nature of ICT-based platforms shows itself in the evolution of information markets. That is, firms that seek to expand services to a broader audience are likely to achieve economies of scale and scope (as initial product development is costly) because subsequent distribution tends to have low marginal costs (Greenstein, 2015). As a consequence, four structural trends have emerged across digital content industries. First, established value chains are changing, particularly at the distribution level. This condition has resulted in deeper disintermediation (and re-intermediation, too) as old (physical) distribution mechanisms are replaced by new (digital) ones. Second, new intermediaries are often participants in established value chains. Third, content industries face declining revenues from traditional channels, forcing them to market an increasing range of products via mobile platforms. Finally, digital content services are sold directly to consumers via proprietary Web sites (games, music, video, and films), and publishers deal directly with libraries (scientific publishing) (McCulluogh, 2018; Parker et al., 2017).

China is an excellent example of the transcendence of digitization. Due to its enormous market size, many ICT applications have had a substantial economic and social impact on Chinese people. The country's ICT system is now playing a fundamental role in the interlinking and merging of different technologies (OECD, 2017). Among the emerging digital technologies are ubiquitous networks, making it possible to follow persons and objects and provide real-time tracking, storing, and processing information. Moreover, Chinese authorities have sought to enable network technologies such as radio frequency identification and other sensor technologies to become increasingly affordable. Hence, investment is rising, and applications are moving into commercial use. Also, China has made quite impressive strides in location-based services by using various position-determining technologies to follow objects and people's locus. The three most common applications are navigation, asset tracking, and criminal surveillance (Hong, 2017).

By realizing the power and ubiquity of digital applications, one can argue that rapid technological change must play a fundamental role in reinforcing digital firms' value chains. Following Parket et al. (2017), we can define three types of digital convergence. 1. Horizontal convergence across existing platforms, such as cable, telecommunication, or wireless. 2. Vertical convergence, which changes the roles along the value chain, e.g., for video delivery, and 3. Platform convergence on the mobile Internet works as a universal platform. Therefore, we shall discuss the effects of digitization on four traditional American industrial sectors.

\section{The Impact of Digitization on Traditional Industries}

Digitization generally relates to the pure analog-to-digital conversion of existing media and documents. For the most part, information technology enhances efficiency when digitized data is used to automate processes, thus enabling better accessibility. Typical applications include photograph scanning, analog music encoding, or converting a print paper report into a portable file document (PDF). All these processes mean data is not altered; it is now encoded in a digital format. Therefore, the widespread diffusion of information technologies has already made a remarkable impact on several communication-prone industries. Among those more severely affected are paper and printing manufacturing, the publishing industry, and airborne broadcasting.

Since long ago, industries have been accustomed to dealing with periodic economic booms and busts, which temporarily affected the economy. But the advent of the Internet has been a gamechanger. For example, print media's digitization has discouraged customers from buying paperbased products (Abaidi \& Vernette, 2018). For some customers, especially the younger ones, the 
consumption of tangible items has turned into a cumbersome and expensive practice, so digital content has become their preferred choice (Meffert et al., 2013). Therefore, current consumption trends have slowed down sales for those industries involved in creating and delivering tangible items, thus opening up market opportunities for virtual products and services.

For example, until the advent of the Internet, mail was perhaps the one central government service that touched every citizen daily. In the days of the Roman Empire, the extensive system of messenger routes served to knit the Empire together. Indeed, the post office is still the only government building in many small American towns. Post offices and postal services have played a significant role in social cohesion for a long time. More recently, the post used to be the primary vehicle for communication and marketing. Nowadays, the post office serves distant rural areas and sometimes serves as a focus of important political events (Crew, Parcu \& Brennan, 2017).

In the past, a country's income and demographic factors were deemed the fundamental drivers of growth in physical mail. The larger a country's population and the higher its income, the larger the mail volumes could be expected to be. And that link existed because there were no substitutes to mail until the advent of the broadband revolution. Today, electronic communications can be used to substitute for physical mail in several circumstances: for example, e-mails substitute letters; and invoices, statements, and bills are now sent electronically, whereas direct marketers use electronic communications rather than print leaflets, and magazines and newspapers are increasingly distributed electronically on alternative platforms such as mobile devices (Abaidi \& Vernette, 2018; Crew et al., 2017; Mayinka et al., 2015; Meffert et al., 2013).

Besides, digitization offers several advantages. First, businesses can incentivize consumers to move away from paper bills and statements by sharing some cost savings with consumers (thus lowering prices). Second, they can also switch to delivering all relevant information through digital means. Third, governments can transfer citizen/public face-to-face interactions to online-only processes, such as filing permits and tax records (OECD, 2017). In any case, economic crises have always created incentives for both firms and governments to cut costs, as the recent COVID-19 pandemic showed (Herath \& Herath, 2020).

\section{Methodology and Data Collection}

\subsection{Description}

This study has an exploratory character. The research approach follows a time-series analysis that draws on the yearly statistics published by the Occupational Employment Statistics (OES) Survey produced for the Bureau of Labor Statistics of the U.S. Department of Labor, available at https://data.bls.gov/oes/\#/home.

We focus our analysis on four industries: 1) Pulp, Paper, Paperboard Mills, or Paper in short (NAICS Code 3221). 2) Printing and Related Support Activities, or Printing (NAICS 3231); 3) Newspaper, Periodical, Book, and Directory Publishers, or Publishing (NAICS 5111); and 4) Radio and Television Broadcasting, or Broadcasting in short (NAICS 5151). We consider that these industries can serve as good examples of the pre-internet economy.

\subsection{Data Selection and Collection}

The information provided by the OES Survey includes economic variables for the U.S. industry based on the North American Industry Classification System (NAICS codes). Yet, a 
methodological caveat is worthy of saying. The OES website has offered industrial data since 1983. Still, we confine our analysis to the 2004-2018 period to mainly focus on the effects of digitization on employment and salary at that time.

\subsection{Pulp, Paper, and Paperboard Mills}

This industry group comprises establishments primarily manufacturing pulp, paper, or paperboard. It is worth noting that the production of cardboard boxes is not included in this sector, even though the fabrication of cardboard boxes has experienced a growing demand from the Internet through sales generated via e-commerce. According to the NAICS Association, at the end of 2018, there were 2,859 commercial businesses registered in four subsectors of the paper manufacturing industry, as the following table shows.

Table 1. Pulp, Paper, and Paperboard Mills (NAICS 3221).

\begin{tabular}{llc}
\hline 6-digit NAICS & Description & Number of Businesses (2018) \\
\hline 322110 & Pulp Mills & 339 \\
322121 & Paper (except Newsprint) Mills & 1,775 \\
322122 & Newsprint Mills & 30 \\
322130 & Paperboard Mills & 715 \\
3221 & Total & 2,859 \\
\hline
\end{tabular}

Source: NAICS Association (data available at https://www.naics.com/naics-codedescription/?code=3221)

For the paper industry, the Internet has changed information availability and physical manufacturing. In particular, Andrés, Zentner \& Zentner (2014) point out that ICT has actually impacted industrial production. They argue that the following activities have likely displaced paper consumption. 1) reading online newspapers and magazines, 2) adopting paperless billing, 3) receiving online advertising, 4) consulting online phonebooks, 5) sending e-mails, 6) buying ebooks, and 7) creating and sharing electronic documents. Using country-level panel data on Internet penetration and paper consumption, they tested these effects disaggregated into various paper categories. They found that the Internet reduces consumption for the paper categories that are more likely to be affected, such as paper used to print newspapers, books, and magazines. Interestingly, growing Internet adoption does not significantly impact sanitary paper consumption (Andrés et al., 2014).

\subsection{Printing and Related Support Activities}

Businesses in the printing and related activities are devoted to manufacturing newspapers, books, labels, business cards, stationery, business forms, and other materials. Activities also include realizing support processes such as data imaging, platemaking services, and bookbinding. Therefore, this industry group comprises business units primarily in handling physical paper to manufacture printed material. According to the NAICS Association, as of the end of 2018, there were 51,200 commercial establishments registered in four subsectors. These figures are shown in the following table. 
Table 2. Printing and Related Support Activities (NAICS 3231)

\begin{tabular}{llc}
\hline 6-digit NAICS & Description & Number of Businesses (2018) \\
\hline 323111 & Commercial Printing (not Screen/Books) & 42,763 \\
323113 & Commercial Screen Printing & 6,388 \\
323117 & Books Printing & 373 \\
323120 & Support Activities for Printing & 1,676 \\
3231 & Total & 51,200 \\
\hline
\end{tabular}

Source: NAICS Association (data available at https://www.naics.com/naics-codedescription/?code $=3231$ )

Regarding the impact of technological change, the printing industry has historically been a study case for labor sociologists interested in analyzing working relations based on the printing trades' exemplary craftsmanship and occupational pride. For instance, Kalleberg, Wallace, Loscocco, and colleagues (1987) suggest that printing could be considered as an anachronism in the age of largescale industrial organization. They base this opinion on the venerable traditions of craftsmanship, pride in people's work, and control over the immediate work process that characterize the activity and seemed virtually undaunted by technological change.

However, ICT began transforming the printing business as early as the mid-1980s, encouraging the newspaper production industry's capital consolidation during the 1990s. At that time, employers gained the economic wherewithal to restructure the labor process to their advantage through technological modernization. Consequently, the sector pioneered digital techniques to manufacture printed material (Vogel, 2004).

\subsection{Newspaper, Periodical, Book, and Directory Publishers}

The newspaper, periodical, book, and directory publishers industry edits and designs printed material such as books, magazines, and newspapers. Book publishers also deal with marketing activities and make distribution agreements with other operators in related industries. The U.S. Bureau of Labor Statistics does not consider self-publishing authors in this category because they are classified in the Performers and Creative Artists industry (NAICS 71151).

Intellectual creativity is at the core of the periodicals industry's competitive strength, so it is highly dependent on intellectual property rights protection tools, with publishers seeking to arrange the distribution of their works through copyrights. Publishing businesses may produce their offerings by themselves or via contracting the intellectual work created by others. These items may be published in one or more formats, such as print or electronic form, including their electronic channels.

Firms belonging to this sector may print, reproduce or provide direct links to the offerings or arrange with others to perform such functions. Businesses that print and publish may accept external manufacturing requests for third-party printing jobs. However, publishing is regarded as the primary activity for these firms. According to the NAICS Association, the publishing industry had at the end of 2018 42,111 commercial businesses registered in six subsectors, as the following table shows. 
Table 3. Newspaper, Periodical, Book, And Directory Publishers (NAICS 5111)

\begin{tabular}{llc}
\hline 6-digit NAICS & Description & Number of Businesses (2018) \\
\hline 511110 & Newspaper Publishers & 10,669 \\
511120 & Periodical Publishers & 4,898 \\
511130 & Book Publishers & 5,110 \\
511140 & Directory and Mailing List Publishers & 553 \\
511191 & Greeting Card Publishers & 334 \\
511199 & All Other Publishers & 20,547 \\
5111 & Total & 42,111 \\
\hline
\end{tabular}

Source: NAICS Association (data available at https://www.naics.com/naics-codedescription/?code $=5111$ )

Book publishing, which accounts for about one-quarter of total publishing industry revenues, is composed of two major sectors: educational/professional and trade (otherwise known as general interest), and the Internet, which allows published content to be downloaded into an electronic book device, have gradually altered the traditional economic model, putting the book business under increasing pressure. On the other hand, newspaper companies function as manufacturers and distributors of the editorial content they create, serving as providers to advertisers seeking access to their readers. Newspapers (and printed magazines) derive their revenues from a combination of advertising, subscription, and newsstand sales. However, approximately two-thirds of the average paper's content in the United States is advertising, with 80 percent of revenues derived from paid ads. Vogel points out that newspaper and magazine revenues are sensitive to overall economic conditions (Vogel, 2004, p. 318).

Newspaper profits are determined by the difference between revenues from advertising and subscriptions and labor and newsprint costs. However, newspapers' profitability has struggled as circulation, and classified advertising has receded since households now derive an increasing share of their electronic media information (Abernathy, 2018; Van Der Burg \& Van Den Bulck, 2017).

\subsection{Radio and Television Broadcasting}

Radio and T.V. broadcasters operate studios and facilities that program and deliver audio and visual content to the public via over-the-air (airborne) transmission. The types of programming offered can be made by broadcasters or affiliates outside the industry.

The industry comprises establishments primarily engaged in operating broadcast studios and facilities for over-the-air or satellite radio and television programs. Establishments are often involved in the production or purchase of programs (or generate revenues from the sale of air time to advertisers), donations and subsidies, or the sale of visual content. According to the NAICS Association, as of 2018, the broadcasting industry comprehended 16,049 commercial businesses registered in three subsectors, as the following table shows. 
Table 4. Radio and Television Broadcasting (NAICS 5151)

\begin{tabular}{lll}
\hline 6-digit NAICS & Description & Number of Businesses (2018) \\
\hline 515111 & Radio Networks & 9,113 \\
515112 & Radio Stations & 2,988 \\
515120 & Television Broadcasting & 3,948 \\
5151 & Total & 16,049 \\
\hline
\end{tabular}

Source: NAICS Association (data available at https://www.naics.com/naics-codedescription/?code $=5151$ )

Since World War II, radio and television have been the dominant mass medium in most Western countries. This sector epitomizes much of the glamour purported by the digital revolution. As mentioned earlier, the information industry's three strands-computing, communications, and broadcasting - had evolved historically as separate sectors. But digital convergence between telecommunications and broadcasting has advanced a long trench since the inception of the Internet in 1991. Nonetheless, satellites and cable systems can also be seen as precursors of internet streaming since 1980 (Hesmondhalgh \& Lobato, 2019).

The formal boundary between the Internet and television is delineated by regulation rather than the technology itself. Still, the progress of digitization, first in computing, later in telecommunications, and finally in the broadcasting sector, results from the evolution of products and services now widely available, such as streaming, video-on-demand, and user-generated content (Martel, 2018). Yet, the general decline in viewer numbers for the regular television channels (e.g., U.S. network T.V.) can be attributed to the broader social and cultural consequences of the transition from one or a few to dozens or hundreds of television channels.

As Hesmondhalgh \& Lobato (2019) argue, channels' variety alone cannot help us explain the continued existence of 'hit shows' and newscasts competing over ratings because television has retained its socially and culturally integrative functions despite the Internet.

These functions have been modified, though. Firstly, by multichannel satellite and cable T.V., and secondly, by digitization and web-based audiovisual services. Consequently, there are now new forms of representation, new ways of telling stories, new ways of persuading consumers. That is, digital convergence has opened a whole set of new aesthetic and rhetorical possibilities.

\section{Discussion: Digitization Trends in Four Industries}

Digitization's impact on traditional industries can be assessed through different means. One way is by analyzing the rate of jobs' creation (or destruction) registered in industrial datasets. We take this approach to evaluate the macroeconomic effects on employment due to the digitization of economic activities. Therefore, we restrict our analysis to the 2004-2018 period to keep the consistency of the OES data set, especially after 2003. The following table shows the total yearly employment in each of the four sectors covered. Figures are in thousands.

\subsection{Employment Analysis}

Employment analysis shows that publishing (NAICS 5111) is, by far, the largest employer from the four industries reviewed, followed by printing (NAICS 3231). From 2009 onwards, there has been a constant workforce contraction across the industries under analysis. 
The reduction rate has varied, however. For example, printing (NAICS 3231) expelled almost 232,000 workers in the fourteen years we analyzed, followed by the publishing sector with 185,000. The broadcasting sector produced a lesser reduction (NAICS 5151), which sacked 53,000 employees. In total, the four industries dismissed 606,100 workers from 2004 to 2018. It means that (together) all sectors shrank for little more than a quarter of their 2004 size (25.3 percent). Fig. 1 shows the accumulated total employment during the 14 years under review.

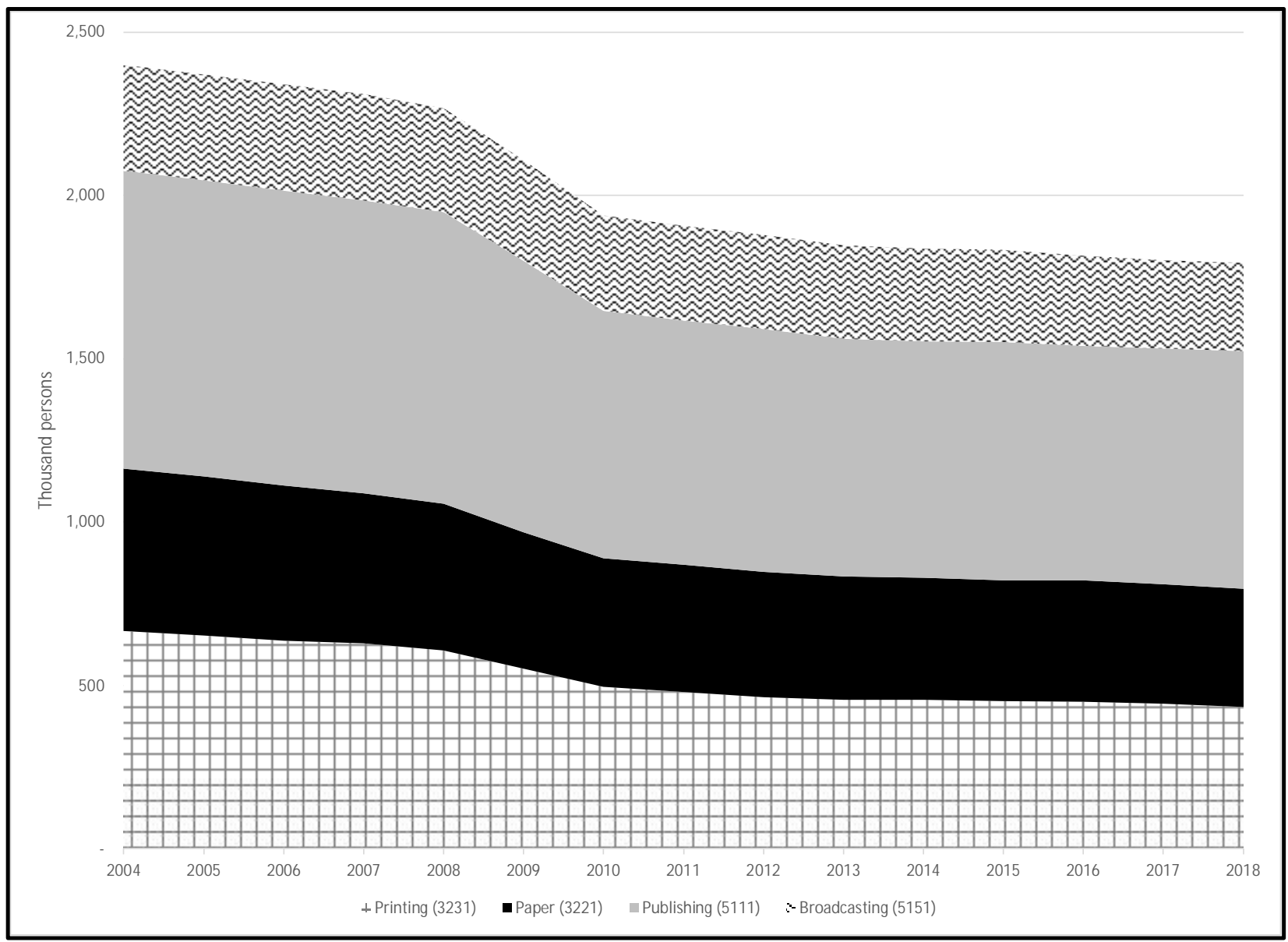

Fig. 1. Total employment, 2004-2018, thousand persons

Source: Author's elaboration based on Bureau of Labor Statistics: www.bls.gov/oes

As Fig. 1 shows, the more significant reduction was produced during the 2008-2009 worldwide financial crisis. Yet, the five industries kept shrinking, although at a slower rate.

The magnitude of these changes needs to be considered in perspective, though. Table V shows the total yearly employment in each of the five sectors from 2004 to 2018. Figures are in thousands. 
Table 5 Four Sectors' Total Employment, 2004-2018 (Thousand Persons)

\begin{tabular}{ccccc}
\hline Year & Paper (3221) & Printing (3231) & Publishing (5111) & Broadcasting (5151) \\
\hline 2004 & 498.1 & 666.5 & 911.5 & 323.7 \\
2005 & 487.6 & 652.4 & 906.1 & 325.4 \\
2006 & 473.3 & 638.1 & 902.1 & 327.7 \\
2007 & 458.9 & 628.9 & 896.3 & 326.0 \\
2008 & 448.5 & 608.0 & 892.1 & 317.9 \\
2009 & 418.0 & 552.2 & 829.3 & 308.2 \\
2010 & 393.5 & 494.8 & 758.1 & 292.0 \\
2011 & 389.5 & 479.0 & 747.9 & 291.2 \\
2012 & 381.8 & 465.2 & 744.3 & 288.4 \\
2013 & 376.4 & 456.5 & 728.1 & 287.0 \\
2014 & 373.7 & 455.9 & 724.4 & 284.8 \\
2015 & 370.8 & 452.1 & 727.7 & 283.7 \\
2016 & 369.8 & 451.5 & 719.1 & 276.3 \\
2017 & 365.8 & 444.3 & 721.7 & 270.0 \\
2018 & 362.1 & 434.8 & 726.2 & 270.5 \\
\hline CAGR & -2.10 & -2.81 & -1.50 & -1.19 \\
\hline
\end{tabular}

Notes: CAGR - compound annual growth rate. Source: Author's elaboration based on the U.S. Bureau of Labor Statistics: www.bls.gov/oes

Regarding the effect of digitization upon industrial performance, our analysis is by no means conclusive because employment was also affected by the economic downturn that the American economy experienced in 2009. So, we shall analyze aggregated wages to contrast these trends.

\subsection{Wage Analysis}

In the case of salaries, the Occupational Employment Statistics Survey reports the mean annual wage for all American industries. Drawing on these data, we prepared a list stating the trends for each sector from 2004 to 2018. Table 6 shows the aggregated data. 
Table 6. Average Annual Wages, 2004-2018 (Thousand U.S. \$)

\begin{tabular}{lllll}
\hline Year & Paper (3221) & Printing (3231) & Publishing (5111) & Broadcasting (5151) \\
\hline 2004 & 38.3 & 35.8 & 49.6 & 45.9 \\
2005 & 39.3 & 36.6 & 51.1 & 48.0 \\
2006 & 40.4 & 37.5 & 53.0 & 48.6 \\
2007 & 41.4 & 38.5 & 55.3 & 51.5 \\
2008 & 42.3 & 39.7 & 58.2 & 54.0 \\
2009 & 43.4 & 40.5 & 60.3 & 55.3 \\
2010 & 44.1 & 40.9 & 62.8 & 55.5 \\
2011 & 44.9 & 41.5 & 64.8 & 55.0 \\
2012 & 45.2 & 41.7 & 66.9 & 56.5 \\
2013 & 45.8 & 42.2 & 69.1 & 59.0 \\
2014 & 46.7 & 42.5 & 71.8 & 61.5 \\
2015 & 47.4 & 43.0 & 74.9 & 63.5 \\
2016 & 48.5 & 43.8 & 78.0 & 65.4 \\
2017 & 49.2 & 44.2 & 81.1 & 66.4 \\
2018 & 50.1 & 45.4 & 84.7 & 68.1 \\
\hline CAGR & 1.80 & 1.60 & 3.64 & 2.67 \\
Net Change & 11.8 & 9.6 & 35.2 & 22.2 \\
\hline
\end{tabular}

Notes: CAGR - compound annual growth rate. Source: Author's elaboration based on the U.S.

Bureau of Labor Statistics: www.bls.gov/oes

As Table 6 shows, all industries were paying higher salaries in 2018 than in 2004 (figures are in current dollars). Internal comparisons are worth analyzing, though. For example, the publishing industry seems to be paying the highest wage. Consequently, publishing workers saw their salary growing by an annual compound rate of 3.64 percent and thus receiving a net increase of 35.2 thousand dollars (on average) in the 14 years under analysis. Another impressive wage performance was the broadcasting industry, with a net gain of 22.2 thousand dollars. This condition means that wages were growing at 2.67 percent each year from 2004 to 2018 .

Regarding the rest, wage increases were not so impressive because they stayed under the 2 percent rate annually. Yet, the printing industry was paying the lower salary among the five sectors, showing a likely stagnant tendency in workers' performance (i.e., productivity). A similar situation happened in the postal and paper industries. These trends are better perceived in Fig. 2, which compares tendencies among the five sectors. 


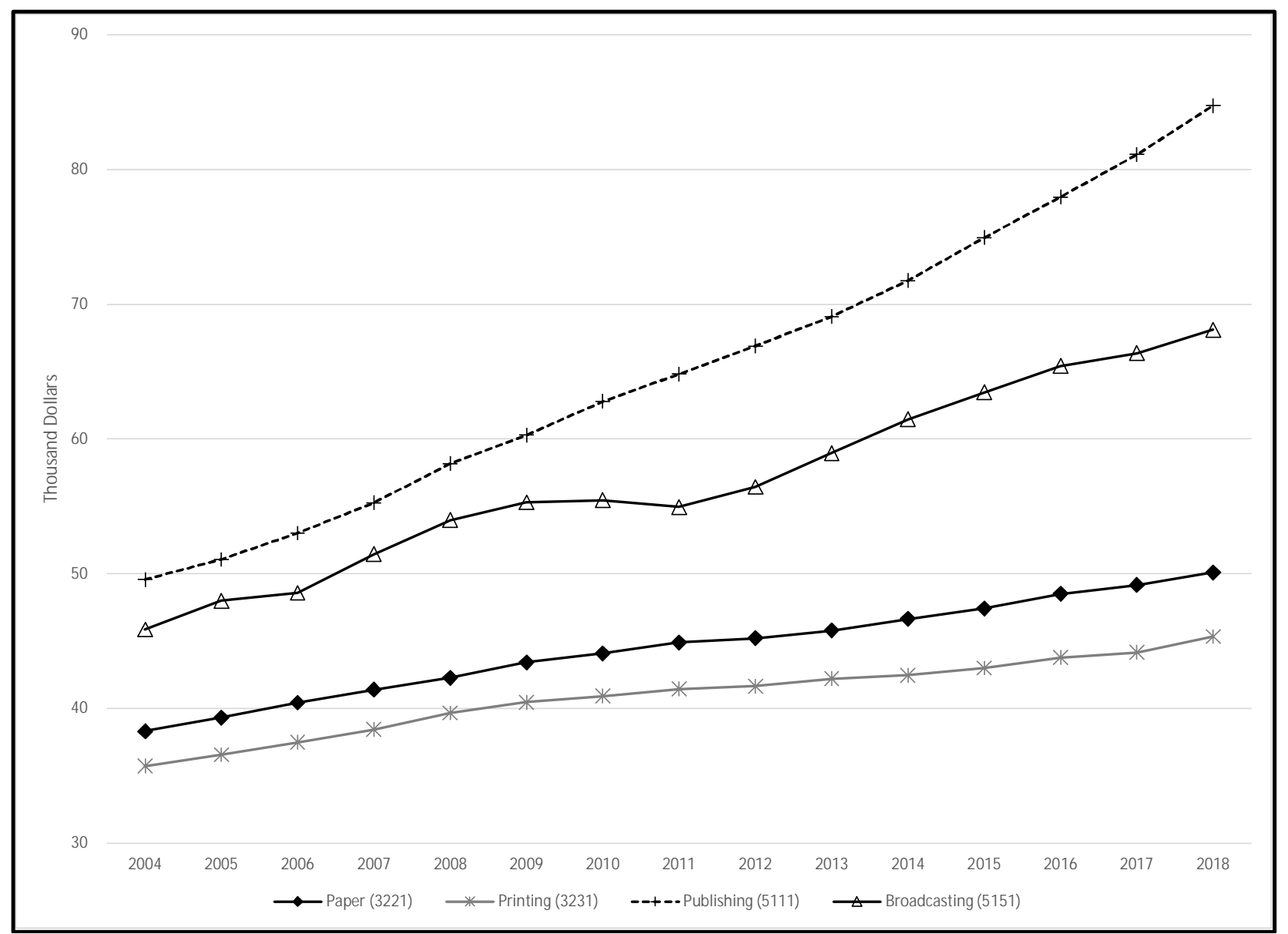

Fig. 2. Mean annual wages, 2004-18, thousand U.S. Dollars

Source: Author's elaboration based on U.S. Bureau of Labor Statistics: www.bls.gov/oes

As Fig. 2 shows, workers in the publishing industry were enjoying a stellar period from 2004 onwards. Even the 2009 crisis did not affect their pay, which influenced the salaries earned in the broadcasting industry. Interestingly, wages in that sector have kept on rising since that year. Finally, workers in the paper and printing industries have been rewarded almost equally, with people in the paper industry enjoying little better payments.

\subsection{Correlation Coefficient Analysis}

To assess the strength of the association between wages and employment, we conduct a statistical test based on Pearson's correlation coefficient for each sector. As Table 7 reports, all ratios are highly correlated and statistically significant. There is a stronger correlation for the paper industry (3221), meaning that the inverse relation between wages and employment was higher for workers in this activity. Table 7 also ranks the order of the association (from first to fourth). 
Table 7. Serial Correlation Between Employment and Wages (E/W)

\begin{tabular}{lllll}
\hline \multicolumn{1}{c}{ Rate } & Paper (3221) & Printing (3231) & Publishing (5111) & Broadcasting (5151) \\
\hline Correlation E/W & $-0.955^{* *}$ & $-0.951^{* *}$ & $-0.894^{* *}$ & $-0.930^{* *}$ \\
\hline Position & First & Second & Fourth & Third \\
\hline
\end{tabular}

Notes: ** Values are significant at the $95 \%$ level.

Overall, trend analysis allows us to devise a contrasting effect in the four industries under examination. While global employment was shrinking, wages were growing. A change in skills composition can only explain this situation. Traditional industries were probably coping with the new market conditions derived from digitization by adopting more sophisticated production practices, which, in turn, increasingly depended on more complex activities and processes. Then, substituting unskilled workers with more talented professionals helped them overcome the trend.

This interpretation is partial, however. A more detailed analysis is needed. For example, controlling for the external economic effects is critical to separate the digitization effect from the environmental conditions; yet, the research carried out in this paper can be a promissory beginning.

\section{Conclusions}

As suggested elsewhere, a healthy industry flourishes in a healthy economy, and following the customary Schumpeterian criterion, one must acknowledge that disruptive innovations must produce healthy economies. ICT's relentless advance shows us that economic activities need to move away from traditional routines and practices. If new offerings are entering the market and challenging traditional ones, businesses must reckon with the best strategy. Usually, this is not the case. Several scholars reported that incumbent industries tend to be stuck in their routines, unable to explore new ways of counterattacking the intruder.

For instance, in the postal service, to gauge the Impact of digital messages, Meschi and colleagues measured the substitution degree between physical and electronic mail, finding a significant negative relationship between broadband penetration and mail volumes (Meschi et al., 2011). They also observe that as broadband functionality improves, it seems reasonable to expect that mail substitution will also increase. They suggest that customers will be active players in this change for the following reasons. First, countries with low broadband services such as e-billing will catch up over time. Hence, ever higher movements of business-to-consumer (B2C) transactions online will increasingly affect mail volumes as more significant segments of the population are comfortable dealing with utilities, banks, and credit card companies in this way. Second, esubstitution, favored by broadband access, is attractive for business customers given the resulting cost reductions over time, a convenience incentive, and the perception of environmental improvement.

This paper analyzed the disruptive effect of digitization under the paradigm of rapidly evolving technological changes. We confirmed that firms producing tangible items, primarily paper-based stuff, have suffered the impact of digital versions of their traditional offerings. Although we only checked for these changes' macroeconomic effects, we can infer that employment and salary changes were induced by the swift deterioration of the five industries' market conditions.

Our analysis considered three industries directly linked with the handling of paper and another one focused on exploiting airborne transmissions: All of them share the common ground of diminishing 
revenues. For example, the printing industry is declining as digital products and services displace printed materials. The problem stems from the accelerated transition towards the digital world that advertising and publishing (the two largest markets for printing) have done since 2015.

Also, many firms are increasingly attracted to online platforms because they are generally less costly to purchase and provide tracking tools for measuring investment returns. In the case of paperbased industries, print advertising expenditure includes spending on advertising in magazines and newspapers. So, when advertising spending declines, newspapers and magazines decrease page output and consolidate operations, negatively affecting the industry's demand. Additional threats are coming from environmental concerns regarding the sustainability of paper production.

A similar situation is happening in the book publishing industry. In recent years sales have stagnated, with revenue increasing only marginally. Although education and academic markets have achieved healthy growth, it has been largely offset by losses in the trade market. This has been true, particularly in the e-book segment, where sales have fallen in recent years after initially surging as the platform reached maturity. Besides, the percentage of books transacted online represents the use of the Internet for services completed originally through a physical medium. As online services increase, authors will be more likely to opt for self-publishing, which is not part of the industry. Given that books are a discretionary household expenditure, a change in total household expenditure influences the purchase of books. When disposable income decreases, individuals are less likely to purchase books to read in their free time or use them as an information source.

The case of radio and television broadcasting is different, however. The television broadcasting industry has grown even though traditional T.V. viewership has been shrinking in the last five years. Nonetheless, free over-the-air broadcasters have benefited from a trend of consumer cordcutting. Meanwhile, overall advertising expenditure has expanded and thus improving operators' profits.

On the other hand, major broadcasters have successfully begun shifting further into digital distribution, which has bolstered revenue amid a drop in traditional audiences. Nonetheless, increased competition hurts industry revenue, as advertisers have more options in alternative media outlets. For example, cable and satellite T.V. services compete with industry operators for advertising dollars and T.V. ratings. Online streaming of T.V. through content providers, such as Netflix, is also on the rise and competes with the industry (see, for example, sales forecasts at https://www.ibisworld.com/).

Finally, digitization is far from being finished. Incessant technological advances seem to guarantee a continuous flux of innovations in the next few years, meaning that more industries can experience unexpected challenges similar to those already faced by paper-based industries.

To some extent, the so-called "creative destruction paradigm" described by Joseph Schumpeter is still valid for industries relying on old manufacturing processes and technologies. Unfortunately, one cannot assume that previous responses can work well under new situations. So, it is better to think that digitization must force traditional firms to compete by offering brand new products and services, thus confirming Schumpeter's dream of promoting innovative entrepreneurs. 


\section{References}

Abaidi, I., \& Vernette, E. (2018). Does Digitalization Create or Reduce Perceived Global Value? Journal of Consumer Marketing, 35(7): 676-687. https://dx.doi.org/10.1108/JCM-09-20172370

Abernathy, P. M. (2018). The Expanding News Desert. Chapel Hill: University of North Carolina Press.

Andrés, L., Zentner, A. \& Zentner, J. (2014). Measuring the Effect of Internet Adoption on Paper Consumption. Washington DC, World Bank.

Christensen, C. M. \& M. Overdorf (2000). Meeting the Challenge of Disruptive Change. Harvard Business Review 78(2): 53-64.

Crew, M. A., Parcu, P. L., \& Brennan, T. (2017). The Changing Postal and Delivery Sector: Towards A Renaissance. Cham: Springer.

Gaines, B. R. (1998). The Learning Curves Underlying Convergence. Technological Forecasting and Social Change 57(1/2): 7-34.

Govindarajan, V. \& Kopalle, P. K. (2006). Disruptiveness of Innovations: Measurement and an Assessment of Reliability and Validity. Strategic Management Journal 27(2): 189-199.

Greenstein, S. M. (2015). How the Internet Became Commercial: Innovation, Privatization, and the Birth of a New Network. Princeton NJ, Princeton University Press.

Herath, T., \& Herath, H. S. B. (2020). Coping with the New Normal Imposed by the COVID-19 Pandemic: Lessons for Technology Management and Governance. Information Systems Management, 37(4): 277-283. https://dx.doi.org/10.1080/10580530.2020.1818902

Hesmondhalgh, D. \& R. Lobato (2019). "Television Device Ecologies, Prominence and Datafication: The Neglected Importance of the Set-Top Box." Media, Culture and Society 41(7): 958-974. https://dx.doi.org/10.1177/0163443719857615

Hong, Y. (2017). Networking China: The Digital Transformation of the Chinese Economy. Urbana IL, University of Illinois Press.

Kalleberg, A. L., Wallace, M., Loscocco, K. A., Leicht, K. T. \& Ehm, H.-H. (1987). The Eclipse of Craft: The Changing Face of Labor in the Newspaper Industry. In Cornfield, D. B. (Ed.), Workers, Managers, and Technological Change: Emerging Patterns of Labor Relations. New York: Plenum Press, 47-71

Lucas, H. C., \& Goh, J. M. (2009). Disruptive Technology: How Kodak Missed the Digital Photography Revolution. Journal of Strategic Information Systems, 18(1): 46-55. https://dx.doi.org/10.1016/j.jsis.2009.01.002

Manyika, J., Ramaswamy, S., Khanna, S. \& Sarrazin, H. (2015). Digital America: A Tale of the Haves and Have-Mores. New York, McKinsey Global Institute.

Martel, F. (2018). Smart: The Digital Century. Delhi: HarperCollins India.

McCullough, B. (2018). How the Internet Happened: From Netscape to the iPhone. New York, Liveright.

Meffert, J., Hazan, E., Wagener, N., Chappuis, B. \& Duncan, E. (2013). iConsumers: Life Online. Telecommunications, Media, and Technology. New York, McKinsey \& Co.

Meschi, M., Cherry, M., Pace, C. \& Petrova, M. (2011). Understanding the impact of e-Subsitution on Letter Mail Volumes: A Multi-Country Panel Study. In Crew, M. A. \& Kleindorfer, P. R. (Eds.), Reinventing the Postal Sector in an Electronic Age. Cheltenham U.K.: Edward Elgar: pp. 47-60

Negroponte, N. (1995). Being Digital. London, Hodder \& Stoughton.

OECD (1992). Telecommunications and Broadcasting: Convergence or Collision? Paris, OECD. 
OECD. (2017). Digital Economy Outlook. Paris: OECD.

Parker, G. G., Van Alstyne, M. W., \& Choudary, S. P. (2017). Platform Revolution: How Networked Markets Are Transforming the Economy and How to Make Them Work for You. New York, W. W. Norton.

Van Der Burg, M., \& Van Den Bulck, H. (2017). Why Are Traditional Newspaper Publishers Still Surviving in the Digital Era? The Impact of Long-Term Trends on the Flemish Newspaper Industry's Financing, 1990-2014. Journal of Media Business Studies, 14(2): 82-115 https://dx.doi.org/10.1080/16522354.2017.1290024

Vogel, H. L. (2004). Entertainment Industry Economics: A Guide for Financial Analysis. New York, Cambridge University Press.

Yoffie, D. B. (1996). Competing in the Age of Digital Convergence. California Management Review, 38(4): 31-53. 